\title{
Effect of Chest Physiotherapy along with Early Mobility after Abdominal Surgery
}

\author{
Md. Feroz Kabir, Sharmila Jahan, Md. Zahid Hossain, Sonjit Kumar Chakrovorty, \\ Altaf Hossain Sarker, Mohammad Anwar Hossain, K. M. Amran Hossain, \\ S. M. Mostafa Kamal, and Sonia Akter
}

\section{ABSTRACT}

The purpose of the study was to evaluate the effect of chest physiotherapy along with early mobility after abdominal surgery. The study was investigating the effect of chest physiotherapy along with early mobility and only chest physiotherapy after major abdominal surgeries on respiratory function, length of hospital stays, pain intensity, oxygen saturation level and status of functional independency (FIM).

Methodology: This was a quasi-experimental study where sixty patients with Lower abdominal surgery conveniently selected from the postoperative unit of the tertiary level specialized hospitals in Dhaka and simple random sampling was used for differentiating the groups. Thirty patients in chest physiotherapy group (control) and thirty in chest physiotherapy along with early mobility group (Experimental). It was measured the respiratory function, length of hospital stays, pain intensity, oxygen saturation level and status of functional independence.

Results: Regarding this study the mean age of the experimental group were $46.7( \pm 18.12)$ years and mean age of control group were $43.4( \pm 15.66)$ years. Mean length of hospital stay was $7.90( \pm 2.078)$ days in experimental group and $11.50( \pm 3.75)$ in control group, and the $p$ value was 0.0016 in experimental group and 0.019 in control group so it was proved that the chest physiotherapy along with early mobilization significantly reduce the duration of hospital stay and chest physiotherapy was also effective. However it was showed that post-operative day-05 experimental group treatment was significantly effective where the $p$ value was $\leq 0.05$ $(p=0.0378)$. So it was absolute showed that the treatment of experimental group was much effective. Study was showed that the effect on improving functional independency level was significantly effective of experimental group of FIM score in all parameters and also in control group also but in comparison it was showed that the experimental group was more effective than control group.

Conclusion: It was identified the significant effectiveness of chest physiotherapy (CPT) along with early mobility rather than only chest physiotherapy after abdominal surgeries. But both groups of participants were showed significant effectiveness. Participants in the CPT along with early mobility exercise after abdominal surgeries showed that it significantly reduces the duration of hospital stay and as well as increase the peripheral oxygen saturation level and also improved functional independence rather than the control group who got only chest physiotherapy.

Keywords: chest physiotherapy, early mobility, abdominal surgery.
Submitted : January 20, 2021

Published : February 9, 2021

ISSN: 2593-8339

DOI: $10.24018 /$ ejmed.2021.3.1.687

\section{Md. Feroz Kabir*}

Jashore University of Science and Technology (JUST), Bangladesh. (email: feroz@just.edu.bd)

Sharmila Jahan

Jashore University of Science and

Technology (JUST), Bangladesh.

(e-mail: sharmilajahandu@ ${ }^{\text {gmail.com) }}$

Md. Zahid Hossain

Jashore University of Science and

Technology (JUST), Bangladesh.

(e-mail: physiozahid@ gmail.com)

Sonjit Kumar Chakrovorty

Dhaka College of Physiotherapy and

Rehabilitation, Bangladesh.

(e-mail: sphddhaka@ gmail.com)

Altaf Hossain Sarker

Dhaka College of Physiotherapy and

Rehabilitation, Bangladesh.

(e-mail: laserphysioas@gmail.com)

Mohammad Anwar Hossain

Bangladesh Health Professions Institute (BHPI), CRP, Savar, Dhaka, Bangladesh.

(e-mail: anwar_physiobd ${ }^{\circledR}$ yahoo.com) K. M. Amran Hossain

Bangladesh Health Professions Institute (BHPI), CRP, Savar, Dhaka, Bangladesh.

(e-mail: amranphysio@gmail.com) S. M. Mostafa Kamal

Saic Institute of Medical Sciences and Technology, Bangladesh.

(e-mail: Physiosohel@gmail.com)

Sonia Akter

BRB Hospitals Ltd., Dhaka, Bangladesh. (e-mail: Soniaakter3987@gmail.com)

*Corresponding Author

\section{INTRODUCTION}

Abdominal surgeries are performed for the diagnosis and treatment of many diseases [1] besides that could be remove cancerous tissue, to resolve visceral tissue perforations or to remove inflammatory bowel segments, benign growths, or vascular aneurysms [2]. Postoperative pulmonary complications (PPCs) following abdominal surgery are very common and are responsible for increased morbidity and mortality as well as the length of hospital stay and healthrelated cost of care [1], [3]. The reported risk rates of postoperative pulmonary complications in upper abdominal 
surgery range from $17 \%$ to $88 \%$. Common postoperative pulmonary complications include atelectasis, hypoxemia, pneumonia, respiratory dysfunction, and pleural effusion [4], [1]. PPCs can be non-infectious for example atelectasis and respiratory failure; or can be infectious like pneumonia [5]. PPCs can lead to delayed patient recovery, prolonged hospitalization as well as increased morbidity and mortality [6]. Smetana states that postoperative pulmonary complications are common, serious, and expensive. Health care costs associated with the treatment of PPCs are 50\% greater than the treating postoperative cardiac complications [7]. Patients who developed PPCs increased stay of 2 weeks compared to those did not develop PPCs [8]. Pulmonary impairments occurring after abdominal surgery persist as a major problem as a result of anesthesia and immobilization. It was found that Postoperative physiotherapy reduce the incidence of postoperative pulmonary complications after open abdominal surgery [9]. Breathing exercises have been routinely used in clinical practice especially in pre and postoperative chest complications [10]. Different kinds of breathing exercises aim to improve the patient's breathing pattern and increase lung expansion, respiratory muscle strength, functional residual capacity, and inspiratory reserve volume, thus preventing or treating PPCs [11].

Prolonged bed rest increased the risk of postoperative complications after surgery. Evidence shows that prolonged immobility increases the risk of venous thromboembolism, result in loss of muscle bulk and strength, increase insulin resistance, reduce pulmonary function and tissue oxygenation and increase levels of hospital-associated depression [12]. The indicating complications increase patient length of hospital stay (LOS) and, in some cases such as venous thrombo-embolization and decreased pulmonary function can be life-threatening [13]. An observational cohort study finding patients were three times more likely to have a PPC diagnosis for each day they did not mobilize away from the bedside [14]. A randomized controlled trial found that in patients following elective abdominal surgery where mobilization was delayed by three days, more physiotherapy input was required, and length of hospital stay was increased by 4.4 days (95\% CI $0.3-8.8$ ) compared with those who ambulated on the first postoperative day [15]. Chest physical therapy plays an important role in the prevention and management of postoperative pulmonary complications [16]. It includes deep breathing exercises, mobilization, postural drainage, percussion and vibration or shaking which were developed to improve bronchial drainage as well as the employment of mechanical breathing devices such as the Incentive Spirometer (IS) which has been introduced into clinical practice [17]. Chest physiotherapy after upper abdominal surgery aims to preserve pulmonary function and reverse physiological and/or functional changes that may occur in the postoperative period due to these complications [18]. Evidence shows that Chest physical therapy appears to improve oxygenation without triggering an increase in pain or other complications [19]. Another important component of care following open abdominal surgery is early mobilization for the best care of the patient [20]. Mobilization in postoperative patients may be defined as low-intensity exercise that aims to elicit cardiopulmonary responses that enhance oxygen transport and assist in the reduction of postoperative pulmonary complications [21]. Early mobilization improved clinical outcomes in patients undergoing open abdominal surgery [9], [21]. Early mobilization forms a routine part of postoperative care and physiotherapists are heavily involved in the initiation of mobilization following UAS, with up to $91 \%$ reporting they always include mobilization in their postoperative treatment. Patients perform little mobilization outside of physiotherapy treatment in the early postoperative period [22] besides another study demonstrated about $48 \%$ of patients mobilized more than $10 \mathrm{~m}$ on the first postoperative day [23]. The purpose of this study was to find out the efficacy of chest physiotherapy along with early mobilization on respiratory functions, length of hospital stay, pain intensity, oxygen saturation level and status of functional independence after abdominal surgery.

\section{Methodology}

\section{A. Study Design and Participants}

It was a quasi-experimental research design implemented from July 2019 to March 2020 and sixty participants of both genders with abdominal surgery and aged 15-70 years were selected conveniently from tertiary level specialized hospital in Dhaka. The random assigned process compiled in group allocation as 30 participants in each group.

\section{B. Study Questionnaire}

A semi-structured questionnaire was used for collecting socio-demographic and medical information and participants were well informed and explained the questionnaire properly. Noninvasive pulse-oximetry was used to measure the level of oxygen saturation within 100 percent screened with fingertip, the tool is consistent and high validity and reliability, spirometer for pulmonary function, Numerical Pain Rating Scale (NPRS) scale for measuring the pain intensity, modified FIM scale to measure the functional independency level by using only transfer and locomotion point and Borg 10 point scale of perceived exertion. Borg rating of perceived exertion (RPE) is an outcome measure scale used in knowing exercise intensity prescription. It is used in monitoring progress and mode of exercise in cardiac patients as well as in other patient populations undergoing rehabilitation and endurance training [24].The translation and language validation of the questionnaire has complied with the standard process of WHO [25].

\section{Ethical Issues}

Ethical permission was obtained from the Institutional review board (BPA IPRR/IRB/01/06/ 2019/0011) of the Institute of physiotherapy, rehabilitation, and research (IPRR). Participation was voluntary, consent was obtained, and confidentiality of the information was assured.

\section{Study Settings}

The study setting was in different tertiary level of hospitals in Dhaka city. 


\section{E. Population and Subjects}

The sample population was the patients with upper abdominal surgery at tertiary level hospitals of Dhaka city from $1^{\text {st }}$ July 2019 to $30^{\text {th }}$ March 2020. The inclusion criteria was patients with upper abdominal surgery, surgery undergo general anesthesia, age above 15 years and below 70 years and willingness to participate. The patient undergoing video laparoscopy, neuromuscular disease, COPD, lower abdominal surgery and unwillingness of patients were excluded.

\section{F. Process of Randomization}

The convenient sampling process was applied for employing sample from the population. The random allocation was compiled for assigning subjects to both groups. As this is a non-randomized parallel group trial the EQUATOR network standards have been ensured. The study was assessor-blinded. For the consistency of the tools, the same assessor performed the pre-test and post-test evaluations.

\section{G. Interventions}

Routine chest physiotherapy procedure: It was consisted of deep breathing exercises (bilateral basal expansion exercise) followed by splinted huff and/or cough the DBEs were performed in four series of five breaths with 3 seconds of sustained breathing.

Early mobilization: (Onset $<48 \mathrm{~h}$ after surgery): It was commenced in the form of sit on the bed-sit out of the bedwalk 5 meter with assistance-walk 15 meter with assistancewalk 30 meter with assistance-walk 30 meter without assistance.

\section{H. Data Collection Procedure}

Participants were randomly assigned in intervention group (Group I) who received early physiotherapy directed to mobilization along with routine post-operative chest physiotherapy such as breathing exercises and splinted coughing, or the control group (Group II) who received only routine postoperative chest physiotherapy (they were mobilized only by the willing to move).

Data was collected through face to face interview using semi structured questionnaire including socio-demographic and medical data. The treatment was provided by the qualified chest physiotherapist. Initial assessment included oxygen saturation level, pulmonary function, pain intensity, functional independence and then it was provided only chest physiotherapy for control group and chest physiotherapy along with early mobilization exercise for experimental group. After given treatment of twice daily for first two post-operative day (POD) and then once daily for up to $7^{\text {th }}$ POD and then compare the outcome by collecting data about oxygen saturation level, pulmonary function, pain intensity band functional independency level but the length of hospital stay was taken from discharge date.

Intervention were provided while subjects were awake (or drowsy but easily woken), had stable blood pressure and heart rate, no dyspnoea at rest and pain less than $8 / 10$ in NPRS. The chest physiotherapy group got lateral basal expansion exercises, sputum clearance techniques, deep breathing, coughing (DB\&C) exercises and they advised to practice the spirometer every 2 hourly. The exercises consisted of at least three coached lateral basal expansion man oeuvres (deep breaths) followed by a cough, huff, or forced expiratory maneuver. Instruction and supervision from the physiotherapist focused on bilateral basal expansion, avoiding upper chest and shoulder elevation, and maximizing expansion of the lower chest diameters during inspiration, with a three second end inspiratory hold, followed by relaxed expiration. This was done with the subject in sitting with the physiotherapist providing bilateral proprioceptive feedback with the hands on the lower ribs. This cycle was repeated at least twice during each treatment. Subjects were encouraged to achieve one or more goals during each treatment, and are encouraged to walk at a speed where they were taking deeper breaths than at rest, at an intensity of at least $6 / 10$ according to the Borg 10 point scale of perceived exertion.

Subjects were encouraged to perform active ankle planter flexion and dorsiflexion exercises, at least 20 times every awaking hour, whilst in bed.

A clear chest was defined as no auscultation or chest radiograph changes, normal temperature, and no sputum. Measureda standardized validated outcome measurement tool for the abdominal surgery, the mobility indicators were used as (1) first day sitting out of bed, (2) first day walking (with or without assistance, including walking on the spot), and (3) first day able to walk 30meter without assistance of another person (with or without a walking aid). Total distance walked, perceived exertion and time spent sitting out of bed were documented daily by the treating physiotherapist on a separate chart.

\section{Data Analysis}

SPSS (Statistical Package for the Social Sciences) software version 16 has been used to analyze the data. The socio-demographic variables have been analyzed by descriptive statistics based on the nature of the data. The non-invasive oximetry score, respirometer score, modified FIM and borg rating for perceived exertion are interval data, and the NPRS are considered as categorical data.

\section{RESULTS}

The baseline characteristics of the participants has described in Table 1. All participants were undergoing hepatobiliary pancreatic surgery under general anesthesia. The following results were presented here as the analytic relation of the objectives and it was presented as descriptively.

The mean duration of hospital stay in experimental group was $7.9( \pm 2.08)$ days and in control group was $11.50( \pm 3.75)$ days. In control group $50 \%$ had no PMH $20 \%$ have DM, $10 \%$ had HD, 20\% had HTN, $40 \%$ smoker and $60 \%$ nonsmoker, $60 \%$ require oxygen support and $40 \%$ do not require oxygen support immediate after operation. In experimental group $40 \%$ had no medical history, $20 \%$ had DM, 10\% had HD, 20\% had HTN, 10\% had RA; 60\% of them require oxygen support after surgery and $50 \%$ of them were smoker. 
TABLE 1: DEMOGRAPHIC CHARACTERISTICS OF THE PARTICIPANTS AT

\begin{tabular}{|c|c|c|}
\hline \multicolumn{3}{|c|}{ BASELINE } \\
\hline Variables & Control group & Treatment group \\
\hline Mean Age & $\begin{array}{c}43.4( \pm 15.66) \\
\text { years }\end{array}$ & $\begin{array}{c}46.7( \pm 18.12) \\
\text { years }\end{array}$ \\
\hline \multicolumn{3}{|l|}{ Gender } \\
\hline Male & $50 \%$ & $50 \%$ \\
\hline Female & $50 \%$ & $50 \%$ \\
\hline \multicolumn{3}{|l|}{ Living area } \\
\hline Rural & $20 \%$ & $10 \%$ \\
\hline Semirural & $30 \%$ & $30 \%$ \\
\hline Urban & $50 \%$ & $60 \%$ \\
\hline \multicolumn{3}{|l|}{ Educational level } \\
\hline Illiterate & $10 \%$ & $10 \%$ \\
\hline Primary & $40 \%$ & $10 \%$ \\
\hline Secondary & $10 \%$ & $30 \%$ \\
\hline Graduation & $40 \%$ & $40 \%$ \\
\hline Post-graduation & 00 & $10 \%$ \\
\hline \multicolumn{3}{|l|}{ Marital status } \\
\hline Married & $90 \%$ & $80 \%$ \\
\hline Unmarried & $10 \%$ & $10 \%$ \\
\hline Widowed & 00 & $10 \%$ \\
\hline
\end{tabular}

TABLE 2: MEDICAL RELATED INFORMATION OF THE PARTICIPANTS

\begin{tabular}{ccc}
\hline Variables & Control group & $\begin{array}{c}\text { Experimental } \\
\text { group }\end{array}$ \\
\hline $\begin{array}{c}\text { Duration of hospital } \\
\text { stay }\end{array}$ & $11.50( \pm 3.75)$ & $7.9( \pm 2.08)$ \\
Past Medical History (PMH) & & \\
DM & $20 \%$ & $20 \%$ \\
HD & $10 \%$ & $10 \%$ \\
HTN & $20 \%$ & $20 \%$ \\
OTHERS & $00 \%$ & $10 \%$ \\
NA & $50 \%$ & $40 \%$ \\
Smoking history & & \\
Smoker & $40 \%$ & $50 \%$ \\
Non smoker & $60 \%$ & $50 \%$ \\
Oxygen require & & $65 \%$ \\
Yes & $60 \%$ & $35 \%$ \\
No & $40 \%$ & \\
\hline
\end{tabular}

TABLE 3: RELATION BETWEEN HOSPITAL STAY AND TREATMENT

\begin{tabular}{|c|c|c|c|c|c|}
\hline \multicolumn{2}{|c|}{$\begin{array}{l}\text { Treatment given to the } \\
\text { participants }\end{array}$} & Mean & SD & $\begin{array}{c}p- \\
\text { value }\end{array}$ & Comments \\
\hline \multirow{2}{*}{$\begin{array}{l}\text { Length } \\
\text { of } \\
\text { hospital } \\
\text { stay after } \\
\text { surgery }\end{array}$} & $\begin{array}{l}\text { Chest therapy } \\
\text { along with } \\
\text { mobility } \\
\text { exercise (E) }\end{array}$ & 7.90 & 2.078 & .0016 & $\begin{array}{l}\text { Both group } \\
\text { intervention is } \\
\text { effective, but } \\
\text { Group ' } E \text { ' is }\end{array}$ \\
\hline & $\begin{array}{l}\text { Chest therapy } \\
\text { (C) }\end{array}$ & 11.50 & 3.749 & .019 & $\begin{array}{l}\text { significantly } \\
\text { more effective } \\
\text { than group ' } \mathrm{C} \text { ' }\end{array}$ \\
\hline
\end{tabular}

It was found that the mean length of hospital stay was $7.90( \pm 2.078)$ days in experimental group and $11.50( \pm 3.75)$ in control group, and the $p$ value was less than 0.05 in both group so it was proved that the chest physiotherapy along with early mobilization significantly reduce the duration of hospital stay but both group of treatment was effective.

\section{A. Effect on Respiratory Function}

\begin{tabular}{ccccc}
\multicolumn{5}{c}{ TABLE 4: SPIROMETER RATING IN EXPERIMENTAL GROUP } \\
\hline \multicolumn{4}{c}{ Experimental group } \\
\hline & Pretest & Posttest POD- & Pretest & Posttest \\
& POD-1 & 1 & POD-7 & POD-7 \\
\hline \multirow{2}{*}{ Mean } & 230 & $295( \pm 59.86)$ & 590 & 740 \\
& $( \pm 85.63)$ & $( \pm 161.24)$ & $( \pm 137.03)$ \\
$\mathrm{t}$ & & 1.9673 & 2.2416 \\
df & & 18 & 18 \\
$P$ value & & 0.0648 & 0.0378 \\
\hline
\end{tabular}

It was showed that post-operative day-01 experimental group treatment was not significantly effective where $p$ value was $\geq 0.05$ ( $p=0.0648)$ however it was showed that post-operative day-07 experimental group treatment was significantly effective where the $p$ value was $\leq 0.05$ $(p=0.0378)$. So, it was absolute showed that the treatment of experimental group was much effective.

\begin{tabular}{ccccc}
\multicolumn{5}{c}{ TABLE 5: SPIROMETER RATING IN CONTROL GROUP } \\
\hline \multicolumn{4}{c}{ Control group } \\
\hline & Pretest & Posttest POD- & Pretest & Posttest \\
& POD-1 & 1 & POD-7 & POD-7 \\
\hline \multirow{2}{*}{ Mean } & 195 & $265( \pm 57.98)$ & 420 & 495 \\
& $( \pm 64.33)$ & $( \pm 161.93)$ & $( \pm 216.60)$ \\
$\mathrm{t}$ & & 2.5560 & 0.8770 \\
$\mathrm{df}$ & & 18 & 18 \\
$P$ value & & 0.0198 & 0.3921 \\
\hline
\end{tabular}

The post-operative day-01 control group treatment was significantly effective where $\mathrm{p}$ value was less than 0.05 $(\mathrm{p}=0.0198)$ however it was showed that post-operative day07 experimental group treatment was not significantly effective where the $p$ value was more than 0.05 $(\mathrm{p}=0.03921)$. Here its making confusion about control group but it also stated clearly that the post-operative day-01 patients usually get high power analgesics and oxygen support so that it showed effectiveness on day-01 and not effective on day-07. Originally control group treatment was less effective which is not significant and it also prove that there has great role of early mobility upon overall fitness and hospital stay also.

\section{B. Pain Status Difference between Groups}

TABLE 6: PAIN Status In EXPERIMENTAL GRoup BEFoRE AND AFTER

\begin{tabular}{ccccc}
\multicolumn{5}{c}{ TREATMENT } \\
\hline & $\begin{array}{c}\text { Treatment group } \\
\text { Pretest } \\
\text { POD1 }\end{array}$ & Posttest POD1 & $\begin{array}{c}\text { Pretest } \\
\text { POD7 }\end{array}$ & $\begin{array}{c}\text { Posttest } \\
\text { POD7 }\end{array}$ \\
\hline Mean & 6.9 & $6,8( \pm 1.135)$ & $2.7( \pm 1.159)$ & $2.6( \pm 1.26)$ \\
& $( \pm 0.74)$ & 0.2335 & 0.1843 \\
$\mathrm{t}$ & & 18 & 18 \\
$\mathrm{df}$ & & 0.8180 & 0.8558 \\
$P$ value & & & \\
\hline
\end{tabular}

Study showed that the experimental group treatment regards post-operative status of pain on day-01 and day-07 was not effective and here was also confounding issues as high power analgesics, pathedine and other types of relaxants and antibiotic. So it's important to do follow-up study for pain issue.

TABLE 7: PAIN STATUS IN CONTROL GROUP BEFORE AND AFTER TREATMENT

\begin{tabular}{|c|c|c|c|c|}
\hline \multicolumn{5}{|c|}{$\frac{\text { TREATMENT }}{\text { Control group }}$} \\
\hline & $\begin{array}{l}\text { Pretest } \\
\text { POD1 }\end{array}$ & PosttestPOD1 & Pretest POD 7 & $\begin{array}{c}\text { Posttest } \\
\text { POD } 7\end{array}$ \\
\hline Mean & $6.1( \pm 0.737)$ & $6.3(1.159)$ & $3.4( \pm 1.074)$ & $3.4( \pm 1.074)$ \\
\hline $\mathrm{t}$ & \multicolumn{2}{|c|}{0.4602} & \multicolumn{2}{|c|}{$\mathrm{t}=0.0000$} \\
\hline df & \multicolumn{2}{|c|}{18} & \multicolumn{2}{|c|}{18} \\
\hline$P$ value & \multicolumn{2}{|c|}{0.6509} & \multicolumn{2}{|c|}{ equals 1.0000} \\
\hline
\end{tabular}

The study showed that the control group of treatment was not significantly effective on post-operative day-01 and day07 also.

The study found that the effect on improving functional independency level was significantly effective of experimental group of FIM score in all parameters and also in control group also but in comparison it was showed that the experimental group was more effective than control group. 
TABLE 8: EFFECT ON FUNCTIONAL INDEPENDENCY LEVEL IN BETWEEN GROUP

\begin{tabular}{|c|c|c|c|c|c|c|c|}
\hline & Treatment given to the participants & $\mathrm{N}$ & Mean & $\mathrm{SD}$ & $\mathrm{t}$ & $\mathrm{df}$ & $P$ value \\
\hline \multirow{2}{*}{$\begin{array}{l}\text { FIM score in } \\
\text { transfer to toilet }\end{array}$} & $\begin{array}{c}\text { Chest physiotherapy along with early } \\
\text { mobilization (E) }\end{array}$ & 30 & 6.80 & .632 & \multirow[t]{2}{*}{4.25} & 18 & .001 \\
\hline & Chest Physiotherapy (C) & 30 & 5.60 & 699 & & 17.82 & .051 \\
\hline \multirow{2}{*}{$\begin{array}{l}\text { FIM score in } \\
\text { transfer taking } \\
\text { shower }\end{array}$} & $\begin{array}{c}\text { Chest physiotherapy along with early } \\
\text { mobilization (E) }\end{array}$ & 30 & 5.50 & .849 & \multirow[t]{2}{*}{1.10} & 18 & .0028 \\
\hline & Chest Physiotherapy (C) & 30 & 5.00 & 1.154 & & 16.54 & .0586 \\
\hline \multirow{2}{*}{$\begin{array}{l}\text { FIM score in } \\
\text { transfer in } \\
\text { waking }\end{array}$} & $\begin{array}{c}\text { Chest physiotherapy along with early } \\
\text { mobilization (E) }\end{array}$ & 30 & 6.80 & .422 & \multirow[t]{2}{*}{1.34} & 18 & .0196 \\
\hline & Chest Physiotherapy (C) & 30 & 6.40 & .843 & & 13.23 & .0502 \\
\hline \multirow{2}{*}{$\begin{array}{l}\text { FIM score in } \\
\text { staring }\end{array}$} & $\begin{array}{c}\text { Chest physiotherapy along with early } \\
\text { mobilization (E) }\end{array}$ & 30 & 5.80 & .789 & \multirow[t]{2}{*}{2.61} & 18 & .0018 \\
\hline & Chest Physiotherapy (C) & 30 & 4.80 & .919 & & 17.58 & .028 \\
\hline
\end{tabular}

\section{Effect on Peripheral Oxygen Saturation Level Between Groups}

TABLE 9: PAIRED SAMPLES STATISTICS IN CONTROL GROUP

\begin{tabular}{|c|c|c|c|c|c|c|}
\hline & Mean & $\mathrm{N}$ & SD & $\mathrm{t}$ & df & $\begin{array}{c}P \\
\text { value }\end{array}$ \\
\hline $\begin{array}{c}\text { Peripheral oxygen } \\
\text { saturation of the } \\
\text { participants in POD1 } \\
\text { pretest \% }\end{array}$ & 89.60 & 30 & 2.50 & & & \\
\hline $\begin{array}{l}\text { Peripheral oxygen } \\
\text { saturation of the } \\
\text { participants in POD1 } \\
\text { posttest } \%\end{array}$ & 94.20 & 30 & 2.74 & -10.17 & 9 & .001 \\
\hline $\begin{array}{c}\text { Peripheral oxygen } \\
\text { saturation of the } \\
\text { participants in POD7 \% }\end{array}$ & 93.50 & 30 & 2.42 & & & \\
\hline $\begin{array}{l}\text { Peripheral oxygen } \\
\text { saturation of the } \\
\text { participants in POD7 } \\
\text { posttest \% }\end{array}$ & 96.90 & 30 & 2.08 & -7.14 & 9 & .001 \\
\hline
\end{tabular}

TABLE 10: PAIRED SAMPLES STATISTICS IN TREATMENT GROUP

\begin{tabular}{|c|c|c|c|c|c|c|}
\hline & Mean & $\mathrm{N}$ & SD & $\mathrm{t}$ & df & $\begin{array}{c}P \\
\text { value }\end{array}$ \\
\hline $\begin{array}{c}\text { Peripheral oxygen } \\
\text { saturation of the } \\
\text { participants in POD1 } \\
\text { pretest } \%\end{array}$ & 92.02 & 10 & 3.85 & & & \\
\hline $\begin{array}{l}\text { Peripheral oxygen } \\
\text { saturation of the } \\
\text { participants in POD1 } \\
\text { posttest } \%\end{array}$ & 94.80 & 10 & 2.66 & -4.33 & 9 & .0001. \\
\hline $\begin{array}{c}\text { Peripheral oxygen } \\
\text { saturation of the } \\
\text { participants in POD7 \% }\end{array}$ & 96.90 & 10 & 1.59 & & & \\
\hline $\begin{array}{l}\text { Peripheral oxygen } \\
\text { saturation of the } \\
\text { participants in POD7 } \\
\text { posttest \% }\end{array}$ & 98.40 & 10 & 1.17 & -4.88 & 9 & .0001 \\
\hline
\end{tabular}

The study showed that both experimental and control group treatment was effective in sense of $\mathrm{O}_{2}$ saturation on day-01 and day-07 also. So it was showed that chest physiotherapy and along with early mobility both was effective for this parameter but experimental was more effective than control group.

\section{Overall Statements}

Chest physiotherapy and along with early mobility treatment was significantly effective for the management of post-operative abdominal surgery patients but combine treatment was more effective than only chest physiotherapy. It also proved that early mobility exercises is highly required for minimizing pain, improving oxygen saturation, decreasing hospital stay and other parameter. So it's recommending to use combine treatment for this type of cases.

\section{E. Discussion}

The studies showed that chest physiotherapy along with early mobility exercise significantly reduce the duration of hospital stay. In compare, breathing exercises have an effect on the worth of the hospital stay and recovery of these patients [25].

The duration of postoperative hospitalization between both groups the finding exposed that the mean of duration of postoperative hospitalization was 7 days for the study group and 9 days for the control group with a statistically significant difference ( $\mathrm{P}$-value $<0.05$ ) between both groups [11]. So, it was showed that the duration of hospital stays significantly lower in treatment group (early mobility) than the control group (conventional chest physiotherapy).

Study reported early mobilization to be a beneficial intervention for patients following UAS [26]. In compare, highlighting the benefits of early mobilization away from the bedside when performed at sufficient intensities [27] and in contrast, another study showed that delaying early mobilization caused an increase in PPCs [28].

In spirometer rating: showed that post-operative day-01 experimental group treatment was not significantly effective where $p$ value was $\geq 0.05$ ( $p=0.0648$ ) however it was showed that post-operative day-07 experimental group treatment was significantly effective where the $p$ value was $\leq 0.05$ $(p=0.0378)$. So it was absolute showed that the treatment of experimental group was much effective.

Study found that ambulation does not significantly increase minute ventilation once the effects of position are taken into consideration. The most likely explanation for ambulation not significantly increasing minute ventilation is that post-operative patients are not being exercised at a high enough intensity [29]. There are also some clinicians who contemplate that if patients are able to walk, there is no need for them to perform deep breathing exercises because ambulation have similar effect to deep breathing exercises on tidal volume has perhaps been reinforced by the findings of studies conducted in patients following cardiac surgery, which concluded that deep breathing exercises offer no advantage over ambulation alone in the prevention of postoperative pulmonary complication. As a result of such findings, it is possible that physiotherapists may choose to Use ambulation on its own in wider post-operative populations.

Another study showed that breathing exercises have a positive effect on FVC, the treatment group was submitted 
to a protocol of localized breathing exercises combined with manual pressure applied by the physical therapist to the patient's thoracic cage during expiration, deep diaphragm breathing, and thoracic cage expansion exercises such as fractional inspiration [30].

Breathing exercises, recently described as respiratory strategies, encompass diaphragm exercise, pursed-lip breathing, changes in body posture to favor ventilation, and active upper and lower limb exercises combined with breathing. The lack of standardization of the types of exercises, number of series, repetitions, intervals, frequency, and times may have influenced the outcome of the studies [25].

Regarding this study it was showed that the effect on improving functional independency level was significantly effective of experimental group of FIM score in all parameters and also in control group also but in comparison it was showed that the experimental group was more effective than control group.

This Study showed that both the chest physiotherapy and chest physiotherapy along with early mobility have no significant effect on pain.

This study found that effective in sense of $\mathrm{O}_{2}$ saturation on day-01 and day-07 also. So, it was showed that chest physiotherapy and along with early mobility both was effective for this parameter but experimental was more effective than control group.

This study is supported by a randomized control trail Chest physiotherapy during the immediate postoperative period following upper abdominal surgery was effective for improving oxygen-hemoglobin saturation without increased abdominal pain. Breathing exercises could be adopted at post-anesthesia care units with benefits for patients [30]. CPT acting with thoracic expansion exercises and diaphragmatic breathing exercises immediately after the UAS seems to improve oxygenation without triggering increase in pain or other complications.

Study recommended that in their study, pulmonary physiotherapy should be supported with mobilization [30]. It has been suggested that early mobilization seems to be more effective than deep breathing exercises for the prevention of PPCs [31]. Study with the patients with upper abdominal surgery reported that daily frequency and duration of mobilization and walking greater than 5 meters on day have positive effects on reducing the length of stay [32]. Another study concluded that mobilization involving an upright position is most beneficial in the early postoperative period and produces evidence of improvement in pulmonary function [33].

\section{CONClusion}

The result of this experimental study has identified the significant effectiveness of chest physiotherapy (CPT) along with early mobility rather than only chest physiotherapy after abdominal surgeries. But both groups of participants were showed significant effectiveness. Participants in the CPT along with early mobility exercise after abdominal surgeries showed that it significantly reduces the duration of hospital stay and as well as increase the peripheral oxygen saturation level rather than the control group who got only chest physiotherapy.

\section{ACKNOWLEDGMENTS}

Authors acknowledge Bijoy Das, Md. Kabir Hossain and Zahid Bin Sultan research assistants for their contribution in data collection and input. The authors are also grateful to Professor Dr. Md. Forhad Hossain for his support in statistical analysis.

\section{AUTHOR CONTRIBUTIONS}

Conceptualization, Data curation, Formal analysis: Md. Feroz Kabir, Sharmila Jahan, Md. Zahid Hossain, Sonjit Kumar Chakrovorty, Altaf Hossain Sarker, Mohammad Anwar Hossain, K M Amran Hossain, SM Mostafa Kamal, Sonia Akter

Funding acquisition, Investigation: Md. Feroz Kabir, Sharmila Jahan, Md. Zahid Hossain, Sonjit Kumar Chakrovorty, Altaf Hossain Sarker

Methodology, Project administration, Resources, Software: Md. Feroz Kabir, Sharmila Jahan, Md. Zahid Hossain, Sonjit Kumar Chakrovorty, Altaf Hossain Sarker, Mohammad Anwar Hossain, K M Amran Hossain, SM Mostafa Kamal

Supervision, Validation, Visualization: Sonjit Kumar Chakrovorty, Altaf Hossain Sarker, Mohammad Anwar Hossain

Writing - original draft: Md. Feroz Kabir, Sharmila Jahan, Md. Zahid Hossain

Writing - review \& editing: Md. Feroz Kabir, Sharmila Jahan, Md. Zahid Hossain, Sonjit Kumar Chakrovorty, Altaf Hossain Sarker, Mohammad Anwar Hossain, K M Amran Hossain, SM Mostafa Kamal, Sonia Akter.

\section{FUNDING}

The author(s) received no specific funding for this work. This is self-funded study.

\section{REFERENCES}

[1] Kumar AS, Alaparthi GK, Augustine AJ, Pazhyaottayil ZC, Ramakrishna A and Krishnakumar SK. Comparison of flow and volume incentive spirometry on pulmonary function and exercise tolerance in open abdominal surgery: a randomized clinical trial Journal of Clinical and Diagnostic Research: JCDR.2016; 10(1), KC01. Available from: https://scholar.google.com/citations?user=WiuKYXwAAAAJ\&hl=en.

[2] Reeve JC and Boden I. The physiotherapy management of patients undergoing abdominal surgery. New Zealand Journal of Physiotherapy.2016; 44(1). DOI: 10.15619/NZJP/44.1.05.

[3] Richardson $J$ and Sabanathan S. Prevention of respiratory complications after abdominal surgery. Thorax.1997; 52(3): 535-43.

[4] Hoogeboom TJ, Dronkers JJ, Hulzebos EH and Van Meeteren NL. Merits of exercise therapy before and after major surgery. Current opinion in anaesthesiology.2014; 161.doi: 10.1097/ACO.0000000000000062.

[5] Denehy L. Surgery for adults. In: Pryor JA, Prasad SA, editors Physiotherapy for respiratory and cardiac problems: adults and pediatrics. 4th ed. Edinburgh: Churchill Livingstone. 2008; Pp. 397 436.2 . 
[6] Lawrence VA, Dhanda R, Hilsenbeck SG and Page CP. Risk of pulmonary complications after elective abdominal surgery. Chest.1996; 110(3):744-750. DOI: 10.1378/chest.110.3.744.

[7] Dimick JB, Chen SL, Taheri PA, Henderson WG, Khuri SF and Campbell Jr DA. Hospital costs associated with surgical complications: a report from the private-sector National Surgical Quality Improvement Program. Journal of the American College of Surgeons.2004; 199(4),

531-537.

DOI: 10.1016/j.jamcollsurg.2004.05.276.

[8] Branson RD. The Scientific Basis for Postoperative Respiratory Care. Respiratory $\quad$ Care.2013; 58(11):1974 $\quad-1984$ DOI: $10.4187 /$ respcare.02832.

[9] Mackay MR, Ellis E and Johnston C. Randomized clinical trial of physiotherapy after open abdominal surgery in high risk patients. Australian Journal of Physiotherapy.2005; 51(3): 151-159. DOI: $10.1016 / \mathrm{s} 0004-9514(05) 70021-0$.

[10] Simmons M, Simmons P. Postoperative respiratory care. In: Hess DR, Maclntyre NR, Galvin WF, Mishoe SC, editors. Respiratory care: principles and practice. 3rd ed. Burlington (MA): Jones \& Bartlett Learning; 2016. p. 921-30.

[11] AbdElgaphar SM and Soliman GH. The Effect of Early Postanesthetic Chest Physiotherapy Nursing Intervention on Patients Undergoing Upper Abdominal Surgery. IOSR Journal of Nursing and Health Science.2015; 4(4): 1-7. DOI: 10.9790/1959-04410107.

[12] Hanekom SD, Brooks D, Denehy L, Fagevik-Olsén M, Hardcastle TC, Manie S and Louw Q. Reaching consensus on the physiotherapeutic management of patients following upper abdominal surgery: a pragmatic approach to interpret equivocal evidence. BMC medical informatics and decision making.2012; 12(1) DOI: 10.1186/1472-6947-12-5.

[13] Kaneda H, Saito Y, Okamoto M, Maniwa T, Minami KI and Imamura H. Early postoperative mobilization with walking at 4 hours after lobectomy in lung cancer patients. General thoracic and cardiovascular $\quad$ surgery.2007; 55(12): 493 498.https://doi.org/10.1007/s11748-007-0169-8.

[14] Sullivan K, Reeve J, Boden I and Lane R. Physiotherapy following emergency abdominal surgery. Actual Problems of Emergency Abdominal Surgery.2016; 109-128. Available from: http://www.intechopen.com/books/actual-problems-of-emergencyabdominal-surgery/physiotherapy-following-emergency-abdominalsurgery.

[15] McCarren B, Alison JA and Herbert RD. Manual vibration increases expiratory flow rate via increased intra pleural pressure in healthy adults: an experimental study. Aust J Physiother.2006; 52 (4): 267-71. DOI: 10.1016/s0004-9514(06)70006-x.

[16] Platell C \& Hall JC. Atelectasis after abdominal surgery. J Am Coll Surgery.1997; 185(6):584-92. DOI: 10.1016/s1072-7515(97)00106-3.

[17] Pryor JA and Prasad AS. Physiotherapy for respiratory and cardiac problems Churchill Livingstone Edinburgh, Elsevier Health Sciences. 2002.

[18] NylandBA,Spilman SK, Halub ME, Lamb KD, Jackson JA and Oetting TW. A preventative respiratory protocol to identify trauma subjects at risk for respiratory compromise on a general in-patient ward. Respir Care.2016; 61(12): 1580-1587. DOI: $10.4187 /$ respcare.04729.

[19] Steven MH, Pryor JA, Webber BA and Hodson MR. Physiotherapy versus cough alone in the treatment of cystic fibrosis. $\mathrm{Nz} \mathrm{J}$ Physiother.1992; 20(2):31,35-37. Available from:https://search.pedro.org.au/search-results/record-detail/1675.

[20] Boden I, Skinner EH, Browning L, Reeve J, Anderson L, Hill C and Denehy L. Preoperative physiotherapy for the prevention of respiratory complications after upper abdominal surgery: pragmatic, double blinded, multicentrer and omised controlled trial, BMJ.2018; 360, j5916. DOI: 10.1136/bmj.j5916.

[21] Zafiropoulos B, Alison JA and McCarren B. Physiological responses to the early mobilization of the intubated, ventilated abdominal surgery patient. Australian Journal of Physiotherapy.2004; 50(2): 95100. DOI: 10.1016/s0004-9514(14)60101-x.

[22] Browning L, Denehy L and Scholes RL. The quantity of early upright mobilisation performed following upper abdominal surgery is low: an observational study. Australian Journal of Physiotherapy.2007; 53(1): 47-52.DOI: 10.1016/s0004-9514(07)70061-2.

[23] Haines KJ, Skinner EH, Berney S and Austin Health POST Study Investigators. Association of postoperative pulmonary complications with delayed mobilization following major abdominal surgery: an observational cohort study. Physiotherapy.2013; 99(2): 119-125. DOI: 10.1016/j.physio.2012.05.013.

[24] Chambers ES, Bridge MW, Jones DA. "Carbohydrate sensing in the human mouth: effects on exercise performance and brain activity". The Journal of Physiology.2009; 587 (8): 1779-1794. DOI: 10.1113/jphysiol.2008.164285. PMC 2683964. PMID 19237430.

[25] Grams ST, Ono LM, Noronha MA, Schivinski CI and Paulin E. Breathing exercises in upper abdominal surgery: a systematic review and meta-analysis. Brazilian Journal of Physical Therapy.2012; 16(5): 345-353. DOI: 10.1590/s1413-35552012005000052.

[26] Hanekom SD, Brooks D, Denehy L, Fagevik-Olsén M, Hardcastle TC, Manie S and Louw Q. Reaching consensus on the physiotherapeutic management of patients following upper abdominal surgery: a pragmatic approach to interpret equivocal evidence. BMC medical informatics and decision making.2012; 12(1). https://doi.org/10.1186/1472-6947-12-5.

[27] Silva YR, Li SK and Rickard MJFX. Does the addition of deep breathing exercises to physiotherapy-directed early mobilisation alter patient outcomes following high-risk open upper abdominal surgery? Cluster randomised controlled trial. Physiotherapy.2013; 99(3):187193. DOI: 10.1016/j.physio.2012.09.006.

[28] Haines KJ, Skinner EH, Berney S and Austin Health POST Study Investigators. Association of postoperative pulmonary complications with delayed mobilization following major abdominal surgery: an observational cohort study. Physiotherapy.2013; 99(2): 119-125. DOI: 10.1016/j.physio.2012.05.013.

[29] Orfanos P, Ellis E and Johnston C. Effects of deep breathing exercises and ambulation on pattern of ventilation in post-operative patients. Australian Journal of Physiotherapy.1999; 45(3): 173-184. DOI: 10.1016/s0004-9514(14)60348-2.

[30] Manzano RM, Carvalho CRFD, Saraiva-Romanholo BM and Vieira JE. Chest physiotherapy during immediate postoperative period among patients undergoing upper abdominal surgery: randomized clinical trial. Sao Paulo Medical Journal.2008; 126(5): 269-273.doi: 10.1590/s1516-31802008000500005.

[31] Brasher PA, McClelland KH, Denehy L and Story I. Does removal of deep breathing exercises from a physiotherapy program including preoperative education and early mobilization after cardiac surgery alter patient outcomes? Australian journal of physiotherapy.2003; 49(3): 165-173.doi: 10.1016/s0004-9514(14)60236-1.

[32] Ahmad AM. Essentials of Physiotherapy after Thoracic Surgery: What Physiotherapists Need to Know? A Narrative Review. The Korean journal of thoracic and cardiovascular surgery.2018; 51(5): 293-307. doi: 10.5090/kjtcs.2018.51.5.293.

[33] Nielsen KG, Holte $\mathrm{K}$ and Kehlet $\mathrm{H}$. Effects of posture on postoperative pulmonary function. Acta Anaesthesiologica Scandinavica.2003; 47(10): 1270-1275.doi: 10.1046/j.13996576.2003.00240.x. 